\title{
Comprometimento Organizacional e Percepções Temporais: Um Estudo sobre Jovens Trabalhadores
}

\section{Organizational Commitment and Time Perceptions: A Study of Young Workers}

\author{
Michelle de Souza Rocha \\ Universidade Federal de Minas Gerais - UFMG - Brasil \\ michelles_rocha@yahoo.com.br \\ ORCID: 0000-0001-6845-8809 \\ Jane Kelly Dantas Barbosa \\ Universidade Federal de Minas Gerais - UFMG - Brasil \\ jane_kdantas@hotmail.com \\ ORCID: 0000-0002-4406-0190 \\ Letícia Rocha Guimarães \\ Universidade Federal de Minas Gerais - UFMG - Brasil \\ leticia_roch@hotmail.com \\ ORCID: 0000-0002-3474-437X \\ Kely César Martins de Paiva \\ Universidade Federal de Minas Gerais - UFMG - Brasil \\ kelypaiva@face.ufmg.br \\ ORCID: 0000-0002-5185-9072
}

Submetido em 22/06/2018; Aprovado em 28/09/2018

\section{Resumo}

O comprometimento organizacional pode ser considerado fator importante para indivíduos e organizações, influenciando as vivências no trabalho e a produtividade. No mesmo sentido, as percepções temporais interferem na maneira pela qual os indivíduos lidam com o trabalho e conduzem suas rotinas. Considerando as idiossincrasias que permeiam os jovens trabalhadores, este estudo teve como objetivo analisar como se encontram configuradas as dimensões do comprometimento organizacional em relação às percepções temporais de jovens trabalhadores assistidos pelo ESPRO Ensino Social Profissionalizante - na cidade de Recife (PE). Para tanto, foi realizada uma pesquisa quantitativa, descritiva e exploratória, com amostra de 229 respondentes, selecionados pelo critério de acessibilidade. 0 instrumento de pesquisa compreende perguntas acerca de informações demográficas e pessoais, escala de comprometimento organizacional (Meyer \& Allen, 1991) e escala de percepções temporais (Bluedorn \& Jaussi, 2007). A análise dos dados foi realizada por meio de estatística descritiva e bivariada. Evidenciou-se que, apesar da presença de correlações significativas no que tange ao comprometimento organizacional e às percepções temporais, essas são consideradas baixas e agrupadas principalmente na dimensão do comprometimento afetivo. Esse tipo de comprometimento foi predominante entre os jovens trabalhadores (média=3,62). Sobre as percepções temporais, estas apresentaram maiores correlações com características pessoais e os jovens revelaram preferências por comportamentos monocrônicos, rápidos e pontuais, com ênfase no passado e arrastamento por liderança, o que pode estar ligado à situação de vulnerabilidade social e ao momento de transição desta fase da vida.

Palavras-chave: Comprometimento Organizacional. Percepções Temporais. Jovens Trabalhadores. Comportamento Humano.

\section{Abstract}

Organizational commitment can be considered important factor for individuals and organizations, that influences work experiences and productivity. Same way, temporal perceptions interfere on how individuals deal with work and conduct their routines. Considering the idiosyncrasies that permeate the 
young workers, this study had as objective analyze how the organizational commitments dimensions and the temporal perceptions of young workers assisted by the ESPRO - Professional Social Teaching in the city of Recife (PE) are related and configured. For that, a descriptive, exploratory and quantitative approach was performed with a sample of 229 respondents, selected by the accessibility criteria. The research tool includes questions about demographic and personal information, organizational commitment scale (Meyer \& Allen, 1991) and temporal perceptions scale (Bluedorn \& Jaussi, 2007). Data analysis was performed using descriptive and bivariate statistics. It was evidenced that, despite the presence of significant correlations regarding organizational commitment and temporal perceptions, these are considered low and grouped mainly in the dimension of affective commitment. This type of commitment was predominant among young workers (mean $=3.62$ ). About the temporal perceptions, they showed greater correlations with personal characteristics and the young workers revealed preferences for monochromic, fast and punctual behaviors, with emphasis on the past and entrainment by leadership, which it may be associated to the situation of social vulnerability and the moment of transition on this phase of life.

Keywords: Organizational Commitment. Temporal Perceptions. Young Workers. Human Behavior.

\section{Introdução}

O acelerado ritmo de transformação das organizações, de seus processos produtivos, de suas estruturas e da gestão, frente a ambientes instáveis e competitivos, incita desafios de lidar com transformações sociais, demográficas, culturais e tecnológicas, o que acarreta novas expectativas, demandas e atitudes na força de trabalho (Leite et al., 2015). Além disso, novas abordagens de estudos para compreensão e adaptação ao que é exigido no ambiente organizacional contemporâneo mostramse relevantes para esta realidade, sendo o comportamento humano algo crucial para o desempenho das organizações.

Estudos relativos ao comprometimento organizacional, que Senge (1998) define como essenciais a uma organização verdadeiramente apta a mudanças e propensa ao sucesso e à perenidade, cresceram significativamente a partir do final da década de 1970 (Botelho \& Paiva, 2011). No Brasil, à medida que os estudos de comprometimento ganharam espaço, algumas relevantes contribuições foram evidenciadas, por exemplo, indicando que um indivíduo comprometido com uma organização cria um vínculo que o leva a fazer sacrifícios em prol da mesma (Silva et al., 2018) e que, quando comprometidos, eles tendem a permanecer mais tempo na organização (Rocha \& Honório, 2015).

De maneira semelhante, estudos sobre percepções temporais se revelam importantes para o entendimento do tempo e de como este influencia os trabalhadores no tocante às atividades administrativas ligadas a crenças, atitudes e comportamentos (Lombardi \& Hanashiro, 2010), considerando que o tempo é tratado majoritariamente como algo natural e não é problematizado, mas ainda possui faces desnudadas. Nesse contexto, estudos envolvendo os trabalhadores possibilitam a compreensão da efetividade do comprometimento com o trabalho e as percepções e atitudes que desenvolvem perante o tempo para realizar suas atividades.

Propostas no sentido de compreender a realidade vivenciada por trabalhadores abrem um leque para que se realizem estudos, por exemplo, com jovens trabalhadores, grupo que pode ser considerado uma "população especial" (Barling et al., 2005) e que enfrenta dificuldades no mercado de trabalho devido à discriminação em função da idade que ocorre de forma sistemática no mundo laboral (Angus \& Reeve, 2006).

Cabe ressaltar que a literatura contemporânea tem apontado que pensar a juventude como fase universal seria desconsiderar a situação e a condição cultural e psicossocial do(a) jovem, que deveriam ser compreendidas como um conjunto social diversificado, em função das diferenças socioculturais. Apesar do papel inequívoco da biologia, estas diferenças socioculturais operariam uma subversão do conceito de adolescência e sua substituição por juventudes, refletindo variações produzidas de formas e condições diferenciadas de ser e se sentir jovem, que imprimem mais ambiguidades do que uma unidade (Coimbra et al., 2005, Veriguine, Basso \& Soares, 2014). Sendo assim, não é possível pensar a juventude em sentido totalmente homogêneo e singular, mas em juventudes que envolvem grupos heterogêneos (Veriguine, Basso \& Soares, 2014).

O trabalho compõe uma parte fundamental deste momento de vida e representa para os (as) jovens um problema (ou solução) significativo do ponto de vista social e pessoal. Esse constitui um importante fator de mobilização, que se manifesta pela reivindicação de um trabalho decente e de um 
emprego estável (OIT, 2009), principalmente para aqueles que se encontram em situação de vulnerabilidade social. Entretanto, observa-se que a realidade vivenciada por muitos jovens brasileiros nesta condição [vulnerabilidade social] é desafiadora, ao passo que enfrentam condições laborais ruins, ocupações pouco qualificadas, baixa remuneração e jornadas de trabalho semanais superiores ao que seria adequado na sua faixa etária (UNFPA, 2010). A situação econômica e social dos jovens ainda é determinante para o ingresso no mercado de trabalho, uma vez que aqueles que dispõem de maiores rendas apresentam menor taxa de desemprego, maior remuneração e menor participação em setores de baixa produtividade (UNFPA, 2010).

Os jovens pesquisados no presente estudo são aqueles que frequentam cursos da Associação de Ensino Social Profissionalizante - ESPRO - na cidade de Recife (PE) e que vivem em situação de vulnerabilidade social. Estes jovens têm idade entre 14 e 24 anos e constituem um grupo com diversas peculiaridades no que tange características pessoais, sociais e laborais. Tais características particularizam o presente estudo em relação ao tempo, pois os jovens podem percebê-lo de maneira diferente de pessoas mais velhas (Vasile, 2015), e em relação às motivações para o comprometimento no trabalho, que podem estar atreladas ao seu contexto socioeconômico.

Diante disso, a presente pesquisa pretende analisar como se encontram configuradas as dimensões do comprometimento organizacional em relação às percepções temporais de jovens trabalhadores assistidos pelo ESPRO, na cidade de Recife (PE).

\section{Referencial Teórico}

\subsection{Comprometimento Organizacional}

Uma longa tradição de estudos objetivou identificar e compreender os fatores pessoais do comportamento humano no trabalho, da qual deriva o conceito de comprometimento (Bastos, 1993). Manter o funcionário comprometido é um dos fatores responsáveis por atribuir qualidade e efetividade dentro da empresa, diminuindo custos com desperdícios e reduzindo a rotatividade de pessoal e o absenteísmo (Dessler, 1996, Walton, 1997), o que sublinha a importância do tema.

A maior parte das definições sobre comprometimento organizacional apresenta em comum o fato de tratar de um estado psicológico que caracteriza a relação do indivíduo com a organização, diminuindo suas chances de abandoná-la (Dias \& Marques, 2002). Comprometimento pode ser entendido como a "força da identificação pessoal e o envolvimento com uma organização particular" (Porter et al., 1974, p. 3). Essa identificação baseia-se em três fatores correlacionados: 1 ) forte crença e aceitação dos valores e objetivos da organização; 2) forte desejo de manter vínculo com a organização e; 3) intenção de se esforçar em prol da organização. Dessa forma, o comprometimento significa mais do que lealdade, envolvendo um relacionamento ativo com a organização, em que cada indivíduo tem a intenção de dar algo de si com o objetivo de contribuir para ela (Mowday et al., 1979).

A investigação sobre as bases do comprometimento organizacional culminou no desenvolvimento do modelo tridimensional de Meyer \& Allen (1987; 1991), que veio substituir o modelo de Mowday, Porter e Steers (1979), predominante até o final dos anos de 1980, em termos de domínio na pesquisa sobre comprometimento (Bastos, 1993). Conforme se procediam as análises das principais correntes teóricas foi detectado que os conceitos de comprometimento pareciam refletir três assuntos: apego afetivo à organização, percepção de custos associados ao abandono da organização e obrigação de permanecer na organização (Meyer \& Allen, 1991).

Nesse sentido, o modelo de Meyer e Allen (1991) reúne as principais correntes, permitindo auxiliar na interpretação das pesquisas existentes e servir como estrutura (framework) para pesquisas futuras (Meyer \& Allen, 1991), com três bases recorrentes para definir o comprometimento: a) afetiva: envolve o apego e a identificação do indivíduo com os valores da organização; b) instrumental ou calculativa: sugere a ligação do indivíduo à organização em resposta à satisfação de necessidades e expectativas dos trabalhadores, como salário e status; e, c) normativa: envolve o comprometimento em permanecer na organização relacionado a padrões morais que definem como o certo a se fazer (Meyer \& Allen, 1991).

Os pontos em comum entre as três dimensões são a visão do comprometimento como um estado psicológico que caracteriza o relacionamento do indivíduo com a organização, além das implicações na decisão de continuar ou não como membro da organização. Um indivíduo pode apresentar diferentes graus das três dimensões agindo de forma simultânea sobre o comportamento (Moscon, Bastos \& Souza, 
2012), existindo um interinfluência entre as dimensões (Meyer et al., 2002, Rocha \& Paiva, 2016). Existem ainda fatores que podem influenciar cada uma das dimensões, nomeados como "antecedentes" e "consequentes" do comprometimento organizacional (Meyer \& Allen, 1991).

As variáveis antecedentes são, na maioria, compostas por características pessoais ou demográficas, como idade e sexo; características do trabalho e características organizacionais, como nível do cargo, tempo na organização, salário e oportunidades de crescimento (Medeiros et al., 2002). Em linhas gerais, as correlações entre comprometimento e características pessoais tendem a ser fracas ou não se mostrarem consistentes, embora elas sejam bastante evidenciadas em pesquisas, enquanto as correlações envolvendo as experiências de trabalho geralmente são mais fortes (principalmente no tangente ao comprometimento afetivo) do que as características pessoais (Meyer \& Allen, 1991; Meyer et al., 2002).

As variáveis consequentes, por sua vez, estão ligadas principalmente à possibilidade de turnover e ao absenteísmo, para as quais são encontradas correlações negativas para todos os tipos de comprometimento com o turnover e a intenção de turnover (Meyer \& Allen, 1991). 0 comprometimento organizacional afetivo é um preditor importante para o desempenho do empregado e para a diminuição na intenção de rotatividade (Silva, Capellozza \& Costa, 2014). No caso do absenteísmo, encontra-se correlação negativa apenas para a dimensão afetiva e discretamente positiva para as demais (Meyer et al., 2002).

O comprometimento dos indivíduos pode ter relação com as formas heterogêneas e preferências de lidar com o tempo, uma vez que elas levam a uma diversidade no ambiente de trabalho e o afetam, podendo interferir em resultados, relacionamentos, lideranças e grupos de trabalho (Lombardi \& Hanashiro, 2010). Sendo assim, a seguir são abordadas as percepções temporais e sua relação com a organização.

\subsection{Percepções Temporais}

O tempo constitui alvo de estudos dos mais diversos campos do conhecimento, como religião, arte, psicologia, sociologia, antropologia e biologia, sendo os estudos da física e da filosofia os mais profícuos (Paiva \& Souza, 2016; Elias, 1998). Há ainda pouca pesquisa na Administração sobre essa temática, apesar de o tempo ser considerado um aspecto chave no ambiente organizacional (Thompson, 1991). Grande parte dos conceitos relacionados à administração envolve o tempo, como aqueles relacionados à gestão, planejamento, finanças, produção e marketing. Desse modo, as atividades administrativas estão ligadas a crenças, atitudes e comportamentos em relação ao tempo (Lombardi \& Hanashiro, 2010), demonstrando que o mesmo constitui terreno fértil para estudos organizacionais (Paiva et al., 2013, Paiva \& Souza, 2016, Barbosa, 2017).

0 tempo pode ser percebido e vivido de formas heterogêneas pelos indivíduos (Bluedorn \& Jaussi, 2007) e há uma diferenciação entre tempo subjetivo e tempo objetivo, contradizendo a visão de que o tempo é o "mesmo para todos", pois quando se realiza alguma atividade que atrai ou provoca emoções positivas, tem-se a sensação de que o tempo passa mais rápido, entretanto, diante de atividades pouco atrativas ou que causam emoções negativas, parece que o tempo passa extremamente devagar (Vasile, 2015).

Elencam-se cinco dimensões temporais relacionadas às preferências dos sujeitos ao lidar com o tempo: policronicidade, velocidade, pontualidade, profundidade e arrastamento (Bluedorn \& Jaussi; 2007). Dentre elas, a policronicidade é destacada como a mais importante, envolvendo uma preferência do sujeito, seja consciente ou inconsciente, de se envolver em uma ou diversas atividades simultaneamente. Em um contínuo, numa extremidade estão as pessoas policrônicas, que preferem se envolver em diversas atividades no mesmo período de tempo, de forma intercalada ou sobreposta; enquanto na outra extremidade estão as pessoas monocrônicas, que preferem chegar ao fim de cada tarefa para então iniciar outra (Bluedorn \& Jaussi, 2007).

A dimensão temporal da velocidade trata da frequência ou número de atividades realizadas em uma unidade de tempo (Bluedorn \& Jaussi, 2007). Essa dimensão também pode ser representada por um contínuo, com graus diferenciados, que pode variar de rápido a lento. A preferência por velocidade pode ser associada a traços de personalidade, como impulsividade e assunção de riscos; à cultura do grupo estratégico do qual a organização faz parte, da indústria e do país como um todo; ao tamanho e à estrutura organizacional; e, ainda, aos mecanismos de recompensa financeira que podem influenciar no aumento na velocidade de execução das tarefas (Bluedorn \& Jaussi, 2007). 
Destaca-se a interligação das duas primeiras dimensões temporais, policronicidade e velocidade, cuja relação pode resultar em quatro tipos de comportamento, quais sejam: monocronia acelerada, relacionada à velocidade alta e monocronia alta; monocronia metódica, relacionada à velocidade baixa e baixa monocronia; policronia acelerada, ligada à alta velocidade e alta policronia; e policronia clássica, ligada à baixa velocidade e alta policronia (Bluedorn \& Jaussi, 2007).

A terceira dimensão é a pontualidade, que se refere ao sujeito estar no "tempo" certo, ser pontual, cumprir horários, prazos, metas e compromissos. Essa dimensão pode ser entendida como objetiva e mensurável, sendo passível de medição através de relógios e calendários. Não obstante, possui elementos de construção social e depende de fatores individuais e contextuais (Bluedorn \& Jaussi, 2007).

Já a quarta dimensão, profundidade temporal, se refere à distância temporal considerada pelo indivíduo entre passado e futuro, para se posicionar frente aos acontecimentos, em que ele possui maior relação com um desses reinos temporais. De acordo com Bluedorn e Jaussi $(2007$, p. 206) a profundidade temporal "inclui as distâncias combinadas no passado e futuro (profundidade temporal total); no entanto, também é permitido falar de 'profundidade temporal futura' ou 'profundidade temporal passada', se um desses reinos temporais é o principal tema de interesse". Cabe ressaltar que esta dimensão tende a envolver maior dificuldade na operacionalização de uma preferência (Paiva et al., 2013, Barbosa, 2017), o que pode ser vinculado à compressão tempo-espaço crescente na vida moderna (Bauman, 2007).

E, por fim, a quinta dimensão temporal abordada por Bluedorn \& Jaussi (2007) é o arrastamento, que se relaciona aos ritmos e aos seus ajustamentos. 0 ajustamento do ritmo a outra atividade ou a outrem pode ocorrer de três formas: sincronia, na qual os ritmos são correspondentes; liderança, na qual um ritmo mais poderoso ou forte influencia o ritmo "arrastado" a ocorrer antes; e condução, na qual o ritmo mais poderoso ou forte "arrasta" os correspondentes que ocorrem depois. Nessa dimensão temporal é perceptível a influência das relações de poder na vivência do tempo, considerando que o arrastamento envolve hierarquias e conflitos provenientes da divisão de poder no âmbito organizacional (Paiva \& Souza, 2016).

O entendimento sobre o tempo não é único e consensual entre as pessoas, e sim fonte de percepções e vivências diferentes que dependem do contexto e das características de cada sujeito, "variando de acordo com gênero, geração a que pertence, posição social, cultura e posição hierárquica nas organizações" (Paiva et al., 2011, p. 668). Pessoas jovens, por exemplo, tendem a perceber o tempo de maneira diferente de pessoas mais velhas (Vasile, 2015), sendo que o contexto a que estão submetidas também pode influenciar essa percepção.

Tendo em vista os conceitos teóricos desenvolvidos, passa-se à descrição da metodologia empregada na presente pesquisa, que aborda comprometimento organizacional e percepções temporais em relação a jovens trabalhadores em situação de vulnerabilidade social.

\section{Método}

A pesquisa realizada teve caráter quantitativo, descritivo e exploratório (Vergara, 2004), tendo em vista o objetivo de analisar como se encontram configuradas as dimensões do comprometimento organizacional em relação às percepções temporais de jovens trabalhadores assistidos pelo ESPRO, na cidade de Recife (PE).

As unidades de análise foram o comprometimento organizacional e as percepções temporais dos jovens da filial do ESPRO - Ensino Social Profissionalizante - de Recife. Trata-se de uma organização sem fins lucrativos que atua na capacitação profissional para promover a inclusão de jovens em situação de vulnerabilidade social no mercado de trabalho. As unidades de observação foram os jovens trabalhadores atuantes em diversas empresas parceiras da instituição, de ramos de atuação diversos.

\subsection{Coleta de Dados}

A seleção da amostra obedeceu ao critério de acessibilidade (Vergara, 2004), contando com o auxílio da própria instituição na divulgação e acesso aos jovens. A coleta dos dados foi realizada por meio da aplicação de questionários em papel, de forma presencial no ESPRO, em 2016, e as respostas foram organizadas em planilhas eletrônicas. Todos os jovens receberam informações sobre os objetivos da pesquisa e foi requisitada assinatura de termos de consentimento para participação.

Foram aplicados 239 questionários, mas a amostra final obtida foi de 229 respondentes devido a 
problemas de preenchimento ou respostas ausentes. 0 questionário foi composto por três seções, compreendendo inicialmente perguntas acerca de informações sociodemográficas e profissionais. A segunda seção foi composta pelas escalas de comprometimento organizacional desenvolvidas por Siqueira (2001) e disponibilizadas por Bastos et al. (2008), considerando as versões nacionais para as três bases do comprometimento (Meyer \& Allen, 1991). São elas: Escala de Comprometimento Organizacional Afetivo (ECOA), Escala de Comprometimento Organizacional Normativo (ECON) e Escala de Comprometimento Organizacional Calculativo (ECOC). A Escala ECOC se desdobra em outros quatro subfatores, a saber: Perdas Sociais no Trabalho (PST), Perda de Investimentos Feitos na Organização (PIFO), Perda de Retribuições Organizacionais (PRO) e Perdas Profissionais (PP).

A terceira e última seção integrou a escala de percepção temporal baseada no modelo de Bluedorn \& Jaussi (2007), validado no contexto brasileiro por Paiva et al. (2013), composto por cinco dimensões temporais: policronicidade, velocidade, pontualidade, profundidade e arrastamento, que, por sua vez, se desdobra em sincronia, liderança e condução.

\subsection{Análise de Dados}

Todas as escalas foram compostas por itens a serem avaliados dentro de uma métrica tipo Likert. A escala de comprometimento foi composta por cinco níveis de avaliação e a escala de tempo por seis níveis. Quanto à interpretação dos dados, para a escala de Comprometimento, Siqueira (2001) define que quanto maior o valor do escore médio, mais forte o comprometimento com a organização dentro daquela dimensão. Para a escala de tempo, também são adotados os valores médios, no entanto, a partir de um ponto de corte (média=3,5) consideram-se os dois pólos de cada dimensão. Os limites adotados para interpretação dos resultados estão descritos conforme a tabela 1:

Tabela 1- Valores limites para interpretação de resultados de Comprometimento Organizacional e Percepção Temporal

\begin{tabular}{|c|c|c|c|c|}
\hline Questionário & Dimensões & & Valores (médias) & Interpretação \\
\hline \multirow{7}{*}{$\begin{array}{l}\text { Comprometimento } \\
\text { Organizacional }\end{array}$} & \multicolumn{2}{|l|}{ Afetiva } & & \\
\hline & \multicolumn{2}{|c|}{ Calculativa ou Instrumental } & Acima de 3,5 & Elevado, Forte \\
\hline & & PST & Entre 2,5 e 3,5 & Mediano \\
\hline & & PIFO & Abaixo de 2,5 & Baixo, Frágil \\
\hline & & PRO & & \\
\hline & & PP & & \\
\hline & \multicolumn{3}{|l|}{ Normativa } & \\
\hline \multirow{8}{*}{ Percepção de Tempo } & \multicolumn{2}{|l|}{ Policronia } & & Policrónico/ Monocrônico \\
\hline & \multicolumn{2}{|l|}{ Velocidade } & & Devagar/Rápido \\
\hline & \multicolumn{2}{|l|}{ Pontualidade } & & Pontual/Não-pontual \\
\hline & \multicolumn{2}{|l|}{ Profundidade } & Acima de 3,5 & Passado/ Futuro \\
\hline & \multicolumn{2}{|l|}{ Arrastamento } & Abaixo ou igual a 3,5 & Sem arrastamento/Com arrastamento \\
\hline & \multicolumn{2}{|l|}{ Sincronia } & & Não sincronizado/Sincronizado \\
\hline & \multicolumn{2}{|l|}{ Liderança } & & Não Liderado/Liderado \\
\hline & \multicolumn{2}{|l|}{ Condução } & & Não conduzido/Conduzido \\
\hline
\end{tabular}

Fonte: Dados da pesquisa.

A análise dos dados foi realizada por meio de estatística descritiva e bivariada, através de testes de comparação e de correlação. Para as análises foram utilizados os softwares Statistical Package for the Social Sciences (SPSS), versão 22 e o Microsoft Excel. Para verificação da normalidade dos dados foi utilizado o teste de Kolmogorov-Smirnov (K-S), que resultou na não normalidade da distribuição dos dados e a consequente adoção de ferramental não paramétrico para análise.

\section{Discussão de Resultados}

Nesta seção são apresentados o perfil da amostra, os resultados referentes à análise dos questionários e as correlações entre as categorias sociodemográficas e as dimensões do 
comprometimento e das percepções temporais. Algumas tabelas referentes aos dados podem ser visualizadas na seção Apêndices.

\subsection{Descrição da Amostra}

Em relação ao perfil dos participantes, a maior parte é do sexo feminino $(54,8 \%)$, com idade inferior a 19 anos (45,8\%). 0 estado civil predominante é solteiro (96,9\%), o que é esperado para a faixa etária. Quanto à escolaridade, a maioria possui ensino médio completo $(46,5 \%)$. A maior parte dos participantes se declarou parda $(39,9 \%)$ e branca $(36,4 \%)$ e a renda familiar dos jovens gira entre um e dois salários mínimos (73,5\%).

Em relação aos dados profissionais, a maior parte dos participantes tem entre um mês e um ano de tempo total de trabalho $(73,9 \%)$, correspondendo para muitos à primeira experiência de trabalho 93,3\% afirmaram ter o mesmo tempo na empresa atual, muito próximo dos resultados encontrados também para o tempo no cargo $(92,8 \%)$. Grande parte dos jovens trabalhadores pesquisados encontrase alocada na indústria $(44,4 \%)$, seguido pelas instituições bancárias $(18,7 \%)$.

Dessa forma, o perfil predominante dos participantes é de jovens com idade inferior a 19 anos, do sexo feminino, ensino médio completo, de cor parda, com tempo de trabalho inferior a um ano, sendo essa experiência a primeira de sua carreira, e com renda familiar entre um e dois salários mínimos, o que condiz com o perfil de trabalhadores que o ESPRO atende.

\subsection{Resultados dos Questionários}

O comprometimento organizacional dos jovens trabalhadores, acerca das três dimensões desenvolvidas por Siqueira (2001), retornou médias, conforme podem ser vistas na tabela 2:

Tabela 2 - Médias e interpretação das dimensões do Comprometimento Organizacional

\begin{tabular}{clcccc}
\hline Questionário & \multicolumn{2}{c}{ Dimensões } & Média & Desvio-padrão & Interpretação \\
\hline & Afetivo & & 3,62 & 0,753 & Elevado \\
& Calculativo & & 2,84 & 0,884 & Mediano \\
Comprometimento & & PST & 2,97 & 1,024 & Mediano \\
Organizacional & & PIFO & 2,83 & 1,061 & Mediano \\
& & PRO & 2,79 & 1,003 & Mediano \\
& & PP & 2,81 & 1,020 & Mediano \\
& & & 2,83 & 0,959 & Mediano \\
\hline
\end{tabular}

Fonte: Dados da pesquisa.

De acordo com as médias apuradas é possível afirmar que o comprometimento organizacional dos jovens trabalhadores é predominantemente do tipo afetivo (média=3,62), indicando que esses jovens se identificam com as empresas nas quais trabalham e desejam contribuir de forma ativa para os objetivos organizacionais. 0 comprometimento afetivo contribui ainda para a construção de uma imagem positiva da organização e um sentimento de pertença, além de ser um preditor do desempenho e da diminuição na intenção de rotatividade (Silva, Capellozza \& Costa, 2014). Frente às dificuldades relacionadas à inserção e manutenção desses jovens no mundo do trabalho (UNFPA, 2010) é compreensível o comprometimento afetivo elevado, dada a centralidade que o trabalho possui na vida dos mesmos (Oliveira, 2011), em especial aqueles que vivem em situação de vulnerabilidade social e enxergam no trabalho uma oportunidade de crescimento.

Quanto à dimensão calculativa e suas subdimensões, todas obtiveram classificações medianas, com valores médios entre 2,79 e 2,97, destacando-se a subdimensão "perdas sociais no trabalho" (PST), que atingiu a maior média entre elas. Isso sugere que, diante da possibilidade de deixar o trabalho, a maior preocupação dentro da dimensão calculativa dos jovens está relacionada à perda dos contatos sociais estabelecidos dentro da organização. Tendo em vista o momento do desenvolvimento psicológico dos jovens trabalhadores, as amizades conquistadas no ambiente de trabalho são importantes para constituição de sua identidade como trabalhadores. A dimensão normativa, por sua vez, ligada à permanência na organização por questões que envolvem o sentimento de obrigação moral, obteve a menor média entre as demais, sendo classificada como mediana. Tais achados demonstram que o trabalho vai além de contratos admissionais e demissionais estabelecidos com uma organização, 
estendendo-se a contratos psicológicos e de troca social estabelecidos, esperados ou exigidos de um indivíduo (Apergis, 2016).

Em relação às percepções temporais, a tabela 3 mostra as médias obtidas e a interpretação para cada uma das dimensões.

De acordo com os dados expostos é possível afirmar que os jovens trabalhadores estudados percebem e lidam com o tempo de forma monocrônica, rápida - caracterizando o quadro apontado por Bluedorn \& Jaussi (2007) como "monocronia acelerada"- pontual e com ênfase no passado, sendo expressivas as vivências de arrastamento, principalmente relacionadas à liderança. Apesar de lidar com várias demandas a serem cumpridas, os participantes preferem adotar um comportamento monocrônico, embora acelerado, possivelmente atentando ao aprendizado das atividades e à entrega de forma correta, ou seja, desejando "mostrar serviço". Possuem ainda preocupação com prazos e horários, esforçando-se para serem pontuais. Em relação à profundidade temporal existe ênfase no passado, o que pode indicar uma evidência dos conflitos próprios da juventude que transita entre a infância e a adultez e, ainda, considerando o contexto socioeconômico desses jovens, isso pode indicar uma dificuldade em lidar com o passado de dificuldades enfrentadas.

Tabela 3 - Média e interpretação das dimensões de Percepções Temporais

\begin{tabular}{clccc}
\hline \hline Questionário & Dimensões & Média & $\begin{array}{c}\text { Desvio- } \\
\text { padrão }\end{array}$ & Interpretação \\
\hline \multirow{2}{*}{ Percepção de Tempo } & Policronia & 3,13 & 0,549 & Monocrônico \\
& Velocidade & 3,62 & 0,615 & Rápido \\
& Pontualidade & 4,36 & 0,803 & Pontual \\
& Profundidade & 3,06 & 0,483 & Passado \\
& Arrastamento & 4,25 & 0,742 & Com arrastamento \\
& Sincronia & 4,36 & 0,882 & Sincronizado \\
& Liderança & 4,45 & 0,915 & Liderado \\
& Condução & 4,00 & 0,777 & Conduzido \\
\hline
\end{tabular}

Fonte: Dados da pesquisa.

Em estudo realizado com jovens, também se pontuou essa preferência por um padrão de comportamento contrário ao que deles é esperado (Paiva et. al, 2013). Considerando sua relação com a tecnologia, esperava-se um perfil mais policrônico entre os jovens, uma vez que o perfil de pessoas "multitarefas" aparece como elemento marcante em uma sociedade marcada por flexibilidade e ritmos que impõem um treinamento à velocidade (Leccardi, 2005). Poderia, ainda, ser esperada uma ligação maior com o futuro, sendo comum a máxima de que quando se é jovem ainda "se tem a vida inteira pela frente", entretanto, foi demonstrada maior ligação com o passado. Esses resultados podem estar relacionados à condição social desses jovens, provenientes de famílias de baixa renda e com limitações importantes no acesso à tecnologia, incluídos no mercado em atividades comumente repetitivas e pouco desafiadoras, com vivências de um passado que é marcante e desperta o desejo de alcançar condições de vida melhores do que aquelas vividas por eles e pelos familiares (Veriguine, Basso \& Soares, 2014).

Os jovens percebem-se arrastados pelo tempo de terceiros, demonstrando que seus comportamentos em relação ao tempo são ajustados de acordo com ritmos mais fortes ou arrastantes, principalmente na forma de liderança, possivelmente sendo esses ritmos os dos pais, professores e superiores hierárquicos. Como os jovens se inserem no mercado de trabalho geralmente como aprendizes, auxiliares ou estagiários, representam o mais baixo nível hierárquico da organização, então as relações de poder existentes podem levar a poucas possibilidades de autonomia e criatividade. Além disso, a natureza das atividades exercidas no trabalho, normalmente repetitivas e dependentes de deliberações de superiores, contribui para o arrastamento. No campo pessoal essa percepção é reforçada, pois o jovem vivencia limitações impostas pelos pais ou cuidadores, professores, entre outras figuras de autoridade em seu universo que exercem poder sobre suas decisões.

\subsection{Análise Comparativa e de Correlações dos Resultados}

$\mathrm{Na}$ busca de identificar relações entre os aspectos demográficos dos jovens, as dimensões do comprometimento organizacional e as percepções temporais, foram realizados testes de comparação e 
de correlação entre as médias obtidas para as categorias de sexo, idade, escolaridade, estado civil e cor declarada; e no campo profissional, para tempo total de trabalho, tempo de trabalho na empresa pesquisada e ramo.

Quanto às médias obtidas analisando aspectos demográficos em relação às dimensões do comprometimento, não foram verificadas diferenças significativas entre a idade dos participantes, estado civil e ramo da empresa. Para a categoria demográfica sexo, foram encontradas diferenças estatisticamente significativas (para $p=0,05$ ) para a subdimensão "perdas de investimentos feitos na organização" (PIFO) e para a dimensão normativa do comprometimento, sendo as médias obtidas para o sexo masculino (3,03 e 2,98, respectivamente) superiores ao feminino (2,66 e 2,70), conforme mostra a tabela 4. Apesar da diferença entre os valores, as faixas de interpretação são consideradas iguais, isto é, medianas. Isso sugere que os homens têm uma crença mais negativa em relação à perda do tempo e esforços dedicados à organização e possivelmente possuem uma visão de compromisso mais ligada à obrigação ou retribuição do que o sexo feminino.

Tabela 4 -Estatísticas descritivas das dimensões de comprometimento e resultados dos testes de comparação por sexo

\begin{tabular}{|c|c|c|c|c|}
\hline $\begin{array}{c}\text { Comprometimento } \\
\text { Organizacional }\end{array}$ & Sexo & Média & $\begin{array}{l}\text { Desvio } \\
\text { Padrão }\end{array}$ & $\begin{array}{c}\text { Teste Comparação } \\
(\mathbf{M x F})\end{array}$ \\
\hline \multirow[t]{2}{*}{ Comprom. Afetivo } & Masculino & 3,61 & 0,691 & \multirow{2}{*}{0,425} \\
\hline & Feminino & 3,63 & 0,804 & \\
\hline \multirow[t]{2}{*}{ Comprom. Calculativo } & Masculino & 2,97 & 0,788 & \multirow{2}{*}{0,056} \\
\hline & Feminino & 2,74 & 0,945 & \\
\hline \multirow[t]{2}{*}{ PST } & Masculino & 3,06 & 0,924 & \multirow{2}{*}{0,219} \\
\hline & Feminino & 2,89 & 1,096 & \\
\hline \multirow[t]{2}{*}{ PIFO } & Masculino & 3,03 & 0,952 & \multirow{2}{*}{0,004} \\
\hline & Feminino & 2,66 & 1,121 & \\
\hline \multirow[t]{2}{*}{ PRO } & Masculino & 2,90 & 0,893 & \multirow{2}{*}{0,139} \\
\hline & Feminino & 2,69 & 1,079 & \\
\hline \multirow[t]{2}{*}{ PP } & Masculino & 2,93 & 0,926 & \multirow{2}{*}{0,090} \\
\hline & Feminino & 2,70 & 1,085 & \\
\hline \multirow[t]{2}{*}{ Comprom. normativo } & Masculino & 2,98 & 0,877 & \multirow{2}{*}{0,011} \\
\hline & Feminino & 2,70 & 1,008 & \\
\hline
\end{tabular}

Fonte: Dados da pesquisa.

Na categoria escolaridade foram encontradas diferenças significativas para a dimensão normativa e para a subdimensão "perdas profissionais" (PP) para pessoas com ensino médio incompleto (Tabela 5). Esse grupo obteve maiores médias para as duas dimensões $(3,22$ e 3,28$)$, o que pode sugerir que esse grupo possui maior preocupação com as possíveis perdas relacionadas ao respeito e prestígio conseguidos na empresa atual, além da aprendizagem de tarefas. Da mesma forma do exposto na categoria anterior, esse grupo também sente possuir uma obrigação moral com a empresa atual, possivelmente devido à sensação de fragilidade e instabilidade do emprego.

Tabela 5- Estatísticas descritivas das dimensões de comprometimento e resultados dos testes de comparação por escolaridade

\begin{tabular}{clr|r|c}
\hline \hline $\begin{array}{c}\text { Comprometimento } \\
\text { Organizacional }\end{array}$ & Escolaridade & Média & $\begin{array}{c}\text { Desvio } \\
\text { Padrão }\end{array}$ & $\begin{array}{c}\text { Teste de } \\
\text { comparação }\end{array}$ \\
\hline Comprom. Afetivo & EF completo & 3,50 & 0,707 & \\
& EM incompleto & 3,48 & 0,503 & \\
& EM completo & 3,63 & 0,714 & 0,721 \\
& ES incompleto & 3,65 & 0,825 & \\
& ES completo & 3,43 & 0,806 & \\
\hline Comprom. Calculativo & EF completo & 2,95 & 0,212 & \\
& EM incompleto & 3,20 & 0,791 & \multirow{2}{*}{03} \\
& EM completo & 2,89 & 0,834 & \\
& ES incompleto & 2,82 & 0,937 & \\
& &
\end{tabular}




\begin{tabular}{|c|c|c|c|c|}
\hline & ES completo & 2,15 & 0,792 & \\
\hline \multirow[t]{5}{*}{ PST } & EF completo & 3,00 & 0,000 & \multirow{5}{*}{0,745} \\
\hline & EM incompleto & 3,21 & 0,839 & \\
\hline & EM completo & 3,01 & 0,929 & \\
\hline & ES incompleto & 2,92 & 1,128 & \\
\hline & ES completo & 2,60 & 1,261 & \\
\hline \multirow[t]{5}{*}{ PIFO } & EF completo & 3,10 & 0,566 & \multirow{5}{*}{0,401} \\
\hline & EM incompleto & 3,23 & 0,978 & \\
\hline & EM completo & 2,81 & 1,007 & \\
\hline & ES incompleto & 2,84 & 1,139 & \\
\hline & ES completo & 2,31 & 0,936 & \\
\hline \multirow[t]{5}{*}{ PRO } & EF completo & 3,10 & 0,849 & \multirow{5}{*}{0,091} \\
\hline & EM incompleto & 3,15 & 0,885 & \\
\hline & EM completo & 2,80 & 0,911 & \\
\hline & ES incompleto & 2,80 & 1,099 & \\
\hline & ES completo & 2,00 & 0,865 & \\
\hline \multirow[t]{5}{*}{$\mathrm{PP}$} & EF completo & 2,70 & 0,707 & \multirow{5}{*}{0,006} \\
\hline & EM incompleto & 3,22 & 0,968 & \\
\hline & EM completo & 2,95 & 0,992 & \\
\hline & ES incompleto & 2,70 & 1,017 & \\
\hline & ES completo & 1,76 & 0,776 & \\
\hline \multirow[t]{5}{*}{ Comprom. Normativo } & EF completo & 3,10 & 0,424 & \multirow{5}{*}{0,025} \\
\hline & EM incompleto & 3,28 & 0,782 & \\
\hline & EM completo & 2,95 & 0,961 & \\
\hline & ES incompleto & 2,68 & 0,966 & \\
\hline & ES completo & 2,33 & 0,808 & \\
\hline
\end{tabular}

Fonte: Dados da pesquisa.

Para cor declarada foram encontradas diferenças significativas das médias obtidas entre as categorias, sendo que os participantes que declaram ser de cor "preta" apresentaram maiores médias nas subdimensões PIFO $(3,50)$, PP $(3,39)$, comprometimento calculativo geral $(3,40)$ e comprometimento normativo $(3,46)$. Essas diferenças indicam uma maior preocupação com possíveis perdas de ordem de investimento de trabalho, com consequências econômicas no trabalho em caso de desligamento e maior sentimento de obrigação moral com a empresa. Ainda que a cor preta não seja a que a maioria declara (apenas 6,1\% dos respondentes), ela se destaca na análise, sendo possível inferir que este resultado se dá devido à tripla exclusão social que estes jovens negros vivenciam no mundo laboral (negros, jovens e pobres), redundando em uma maior preocupação com as perdas possíveis em uma situação de desemprego, o que pode ser considerado reflexo da estigmatização reproduzida pela sociedade perante negros, mulheres, homossexuais e pessoas com deficiência (Magalhães, Andrade \& Saraiva, 2017). Os dados para todas as categorias podem ser verificadas na tabela 6.

Tabela 6 - Estatísticas descritivas das dimensões de comprometimento e resultados dos testes de comparação por cor declarada

\begin{tabular}{l|l|c|c|c}
\hline \hline $\begin{array}{c}\text { Comprometimento } \\
\text { Organizacional }\end{array}$ & Cor declarada & Média & $\begin{array}{c}\text { Desvio } \\
\text { Padrão }\end{array}$ & $\begin{array}{c}\text { Teste de } \\
\text { comparação }\end{array}$ \\
\hline & Branca & 3,72 & 0,746 & \\
& Preta & 3,49 & 0,774 & \multirow{2}{*}{ Comprom. Afetivo } \\
& Morena & 3,54 & 0,773 & 0,546 \\
& Parda & 3,57 & 0,770 & \\
& Amarelo (oriental) & 3,77 & 0,464 & \\
Comprom. Calculativo & Branca & 2,70 & 0,860 & \multirow{2}{*}{$\mathbf{0 , 0 3 9}$} \\
& Preta & 3,40 & 0,765 & \\
\cline { 5 - 5 }
\end{tabular}




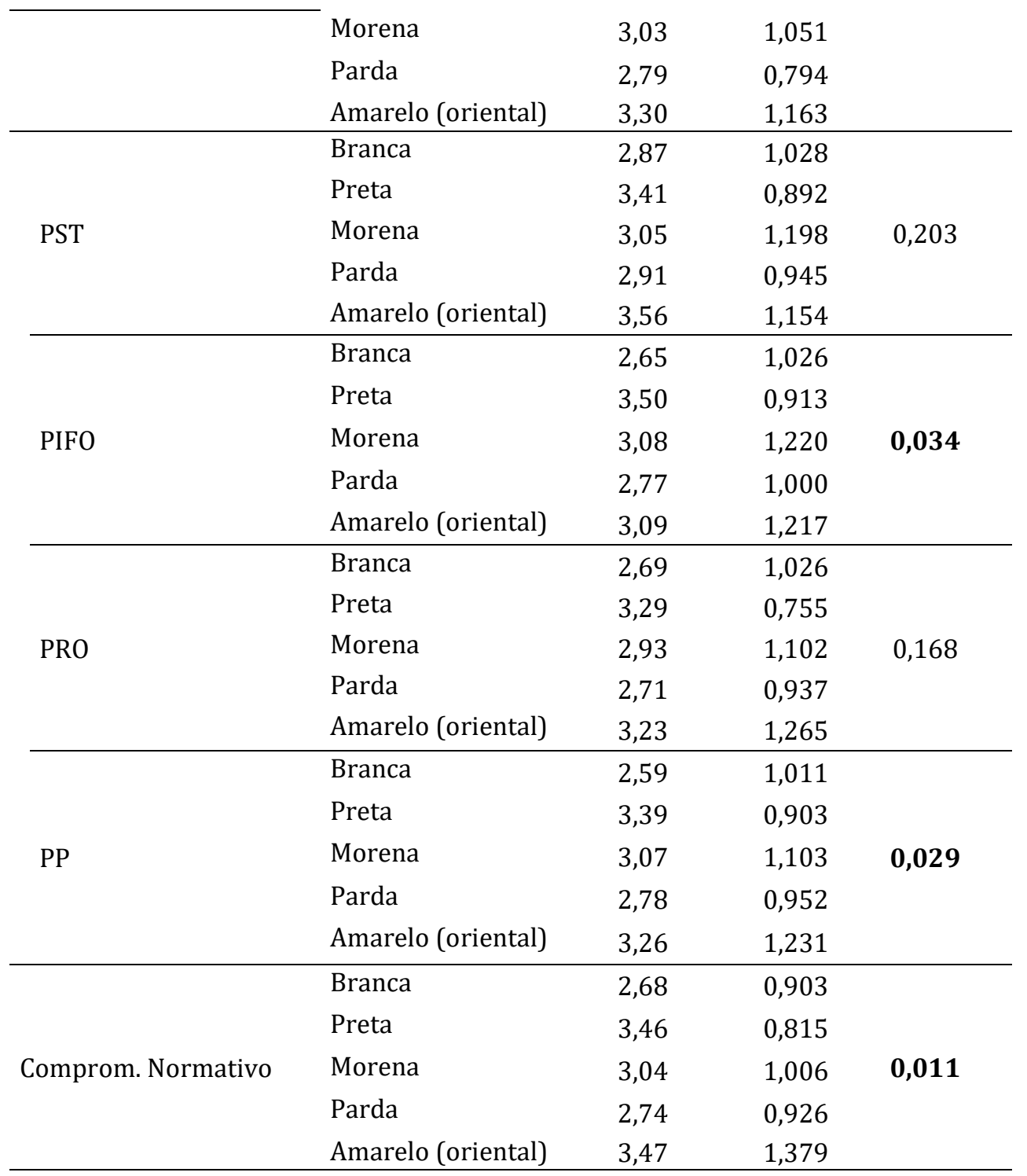

Fonte: Dados da pesquisa.

No tocante ao tempo de permanência no mercado de trabalho, conforme foi verificado no perfil, existe uma proximidade entre o tempo total ou experiência de trabalho e tempo na empresa, devido ao fato de essa ser a primeira experiência para a maioria dos respondentes. Ao verificar as médias obtidas nessas duas categorias foram encontradas diferenças significativas em PIFO $(3,15)$, PP $(3,11)$ e comprometimento calculativo $(3,12)$ para Tempo Total de Trabalho. Em relação ao tempo na empresa foram encontradas diferenças para comprometimento afetivo $(3,76)$, PIFO $(3,05)$, perdas de retribuições na organização (PRO, média=2,96), comprometimento calculativo geral $(3,01)$ e comprometimento normativo $(2,97)$ para o grupo com até 6 meses de experiência (APÊNDICE A). Isso sugere que um menor tempo de trabalho influencia uma visão mais positiva e, ao mesmo tempo, gera maior temor em relação às perdas, possivelmente devido à recenticidade da entrada no mercado de trabalho. Estes achados indicam uma relação do comprometimento com o tempo objetivo, no sentido da quantificação do tempo na organização, e com o tempo subjetivo, no sentido da percepção desse tempo de trabalho influenciar uma visão positiva da empresa, considerando que tempo objetivo e subjetivo se destacam (Vasile, 2015).

Para as percepções temporais foram encontradas diferenças significativas entre as médias encontradas para as categorias sexo, escolaridade e ramo de atuação. 0 sexo feminino apresentou maiores médias para as dimensões de policronicidade $(3,21)$, pontualidade $(4,47)$, profundidade $(3,10)$ e arrastamento $(4,33)$ relacionado à liderança $(4,57)$, conforme tabela 8 . As mulheres tendem a ser mais policrônicas em suas atividades, mais focadas no futuro e mais arrastadas por ações e decisões de superiores. Estes achados estão alinhados ao "modelo" feminino difundido na sociedade (Magalhães, 
Andrade \& Saraiva, 2017), em que a mulher consegue (ou tem que) fazer várias coisas ao mesmo tempo e está mais sujeita a ser "arrastada" pelas relações de poder.

Tabela 7 - Estatísticas descritivas das dimensões de percepções temporais e resultados dos testes de comparação por sexo

\begin{tabular}{|c|c|c|c|c|}
\hline Percepções Temporais & Sexo & Média & $\begin{array}{l}\text { Desvio } \\
\text { Padrão }\end{array}$ & $\begin{array}{c}\text { Teste } \\
\text { Comparação } \\
\text { (MxF) }\end{array}$ \\
\hline \multirow[t]{2}{*}{ Policronia } & Masculino & 3,03 & 0,500 & \multirow{2}{*}{0,007} \\
\hline & Feminino & 3,21 & 0,573 & \\
\hline \multirow[t]{2}{*}{ Velocidade } & Masculino & 3,56 & 0,516 & \multirow{2}{*}{0,154} \\
\hline & Feminino & 3,67 & 0,680 & \\
\hline \multirow[t]{2}{*}{ Pontualidade } & Masculino & 4,22 & 0,743 & \multirow{2}{*}{0,012} \\
\hline & Feminino & 4,47 & 0,834 & \\
\hline \multirow[t]{2}{*}{ Profundidade } & Masculino & 3,02 & 0,494 & \multirow{2}{*}{0,048} \\
\hline & Feminino & 3,10 & 0,469 & \\
\hline \multirow[t]{2}{*}{ Arrastamento } & Masculino & 4,16 & 0,712 & \multirow{2}{*}{0,034} \\
\hline & Feminino & 4,33 & 0,761 & \\
\hline \multirow[t]{2}{*}{ Sincronia } & Masculino & 4,27 & 0,831 & \multirow{2}{*}{0,064} \\
\hline & Feminino & 4,43 & 0,923 & \\
\hline \multirow[t]{2}{*}{ Liderança } & Masculino & 4,29 & 0,856 & \multirow{2}{*}{0,012} \\
\hline & Feminino & 4,57 & 0,942 & \\
\hline \multirow[t]{2}{*}{ Condução } & Masculino & 3,95 & 0,727 & \multirow{2}{*}{0,258} \\
\hline & Feminino & 4,04 & 0,820 & \\
\hline
\end{tabular}

Fonte: Dados da pesquisa.

$\mathrm{Na}$ categoria escolaridade, as diferenças foram encontradas para as dimensões de velocidade $(3,79)$ e arrastamento $(4,44)$, sendo este mais relacionado à liderança $(4,62)$, para o grupo que declarou ter ensino superior incompleto (tabela 9). Esse achado pode sugerir uma ligação entre a tentativa de conciliar as demandas do trabalho e dos estudos em nível superior, exigindo dos jovens maior velocidade na realização de tarefas e comportamentos arrastados por terceiros. Observa-se, assim, que a percepção temporal dos indivíduos pode variar conforme momentos de vida e ambientes específicos onde vivenciam suas experiências, corroborando com a ideia de que o tempo é construído socialmente (Paiva \& Souza, 2016) e percebido de formas heterogêneas pelos sujeitos (Bluedorn \& Jaussi, 2007).

Tabela 8 - Estatísticas descritivas das dimensões de percepções temporais e resultados dos testes de comparação por escolaridade

\begin{tabular}{l|l|r|c|c}
\hline \hline Percepções Temporais & Escolaridade & Média & $\begin{array}{c}\text { Desvio } \\
\text { Padrão }\end{array}$ & $\begin{array}{c}\text { Teste de } \\
\text { comparação }\end{array}$ \\
\hline Policronia & EF completo & 2,80 & 0,424 & \\
& EM incompleto & 2,96 & 0,366 & \multirow{2}{*}{ EM completo } \\
& ES incompleto & 3,10 & 0,567 & 0,302 \\
& ES completo & 3,19 & 0,555 & \\
\hline Velocidade & EF completo & 3,30 & 0,453 & \\
& EM incompleto & 3,28 & 0,430 & \\
& EM completo & 3,52 & 0,556 & $\mathbf{0 , 0 0 6}$ \\
& ES incompleto & 3,79 & 0,665 & \\
& ES completo & 3,49 & 0,520 & \\
\hline Pontualidade & EF completo & 3,75 & 0,212 & \\
& EM incompleto & 4,04 & 0,738 & \multirow{2}{*}{0,240} \\
& EM completo & 4,31 & 0,787 & \\
& ES incompleto & 4,47 & 0,828 & \\
& ES completo & 4,37 & 0,763 & \\
\hline
\end{tabular}




\begin{tabular}{|c|c|c|c|c|}
\hline \multirow[t]{5}{*}{ Profundidade } & EF completo & 2,85 & 0,071 & \multirow{5}{*}{0,084} \\
\hline & EM incompleto & 2,89 & 0,407 & \\
\hline & EM completo & 3,05 & 0,497 & \\
\hline & ES incompleto & 3,10 & 0,471 & \\
\hline & ES completo & 3,08 & 0,555 & \\
\hline \multirow[t]{5}{*}{ Arrastamento } & EF completo & 4,05 & 0,212 & \multirow{5}{*}{0,004} \\
\hline & EM incompleto & 3,63 & 0,771 & \\
\hline & EM completo & 4,16 & 0,741 & \\
\hline & ES incompleto & 4,44 & 0,704 & \\
\hline & ES completo & 4,22 & 0,612 & \\
\hline \multirow[t]{5}{*}{ Sincronia } & EF completo & 3,90 & 0,566 & \multirow{5}{*}{0,020} \\
\hline & EM incompleto & 3,70 & 0,734 & \\
\hline & EM completo & 4,30 & 0,905 & \\
\hline & ES incompleto & 4,51 & 0,864 & \\
\hline & ES completo & 4,46 & 0,688 & \\
\hline \multirow[t]{5}{*}{ Liderança } & EF completo & 4,15 & 0,495 & \multirow{5}{*}{0,037} \\
\hline & EM incompleto & 3,75 & 0,939 & \\
\hline & EM completo & 4,38 & 0,944 & \\
\hline & ES incompleto & 4,62 & 0,827 & \\
\hline & ES completo & 4,35 & 1,012 & \\
\hline \multirow[t]{5}{*}{ Condução } & EF completo & 4,15 & 0,495 & \multirow{5}{*}{0,002} \\
\hline & EM incompleto & 3,47 & 0,815 & \\
\hline & EM completo & 3,86 & 0,735 & \\
\hline & ES incompleto & 4,23 & 0,781 & \\
\hline & ES completo & 3,92 & 0,587 & \\
\hline
\end{tabular}

EF - Ensino Fundamental, EM - Ensino Médio, ES - Ensino Superior

Fonte: Dados da pesquisa.

0 grupo alocado em bancos ou instituições financeiras apresentou maiores médias em relação à velocidade $(3,73)$ e pontualidade $(4,53)$ em comparação às demais áreas de atuação, indicando uma exigência por rapidez (ver APÊNDICE B). A percepção temporal desse grupo e suas preferências podem estar relacionadas diretamente ao ambiente dinâmico desse tipo de instituição, considerando que a percepção do tempo se vincula a um sistema complexo de mecanismos e estratégias desenvolvido pelos indivíduos para lidar com a dinamicidade do ambiente (Vasile, 2015).

A análise das correlações, conforme exposto no APÊNDICE C, retornou valores que variaram entre -0,141 e 0,228, indicando uma correlação baixa entre as dimensões do comprometimento, da percepção temporal e os dados demográficos. Os resultados coadunam com aqueles encontrados em outras pesquisas (Bastos, 1993), que revelam que as correlações entre comprometimento e características pessoais tendem a ser reduzidas. A maior parte das correlações estatisticamente importantes (para $p=0,05$ ou $p=0,01$ ) está concentrada nas categorias ligadas ao tempo de trabalho. Isso confirma os achados de Meyer et al., (2002) que apontam correlações mais positivas para o comprometimento ligado às características do trabalho do que às características pessoais.

Em relação às percepções temporais, por sua vez, elas apresentaram maiores correlações com características pessoais. É possível notar correlações positivas com sexo em relação à policronicidade, pontualidade, profundidade e arrastamento (liderança). A escolaridade também possui destaque ao correlacionar-se positivamente com as dimensões velocidade, profundidade e arrastamento (liderança), reforçando que quanto maior o nível educacional, aprofundam-se os sentimentos de rapidez e de uma maior dependência em relação às ações de outros no seu trabalho e vida cotidiana.

Buscou-se também correlações entre as dimensões do comprometimento e as percepções temporais presentes nessa pesquisa. As correlações estatisticamente significativas encontradas se mostram de baixa intensidade, variando entre -0,131 e 0,379. As dimensões velocidade $(0,194)$, pontualidade $(0,379)$, arrastamento $(0,336)$ e as subdimensões sincronia $(0,285)$, liderança $(0,328)$ e condução $(0,246)$ apresentaram correlações positivas $(p=0,01)$ com o comprometimento afetivo. Esse 
resultado é relevante, pois, considerando que o comprometimento afetivo descreve uma dimensão de natureza eminentemente psicológica (Meyer \& Allen, 1991), isso pode sugerir que a forma como os jovens percebem o tempo pode ser influenciada pela natureza da sua vinculação, gerando efeitos, por exemplo, na percepção da passagem do tempo (rápido ou devagar) (Vasile, 2015), na motivação para o cumprimento de prazos ou no relacionamento com os pares e superiores.

A dimensão temporal policronicidade apresentou correlações significativas negativas com PP ($0,154)$ e comprometimento normativo $(-0,157)$. Já a dimensão profundidade, com PST $(0,134)$, PP (0,131 ) e a dimensão geral do comprometimento calculativo $(-0,143)$, para $p=0,05$. A policronicidade pode refletir o temor dos jovens em relação à perda do controle sobre o próprio aprendizado e consequentes perdas profissionais (PP), o que se relaciona também à dimensão de uma obrigação com a empresa, principalmente no tocante ao seu desempenho nessas atividades. De forma semelhante, a dimensão profundidade em conjunto a possíveis perdas sociais, profissionais e demais calculativas do trabalho, como renda e benefícios, denotam a preocupação com o retorno a uma situação vivida no passado, possivelmente de desemprego e dificuldades, o que foi apontado pelos resultados do questionário.

Diante desses resultados, foram tecidas considerações finais acerca do estudo, que são apresentadas a seguir.

\subsection{Implicações para a Teoria}

As principais contribuições desta pesquisa envolvem a associação dos dois construtos abordados, comprometimento organizacional de Meyer e Allen (1991) e percepções temporais de Bluedorn e Jaussi (2007), a um público idiossincrático, os jovens trabalhadores. Contribui ainda com achados relevantes, como o fato de os jovens abordados apresentarem comprometimento predominantemente afetivo, no qual ocorre forte apego, identificação com os valores da organização e valorização das amizades; bem como preferências por comportamentos monocrônicos e com ênfase no passado. Isto destoa do esperado em um contexto social tecnológico, marcado pela aceleração e compressão do tempo, e contradiz a tendência de carreira sem fronteiras e proteana verificada entre profissionais brasileiros, que enfatiza flexibilidade, mobilidade, envolvimento profissional em detrimento do emocional e planejamento de carreira baseado no futuro (Oliveira \& Gomes, 2014).

\subsection{Implicações para a Prática}

Em relação ao ESPRO, as reflexões levantadas podem contribuir para um maior entendimento acerca da realidade dos jovens no ambiente de trabalho, a fim de buscar alternativas que favoreçam um ambiente satisfatório para o desenvolvimento dos mesmos.

Para as organizações que recebem os jovens, torna-se possível refletir sobre o quê os motiva a serem comprometidos com a organização e quais possibilidades de autorrealização e crescimento podem ser oferecidas a eles, contribuindo para a formação desses futuros trabalhadores. Outrossim, implica reflexões sobre como conciliar as percepções temporais dos jovens com o tipo de trabalho executado e os pares com quem convivem na organização, o que pode evitar conflitos, incompatibilidades e prejuízos à produtividade.

Para os jovens, o estudo propicia reflexões sobre sua situação laboral e os desafios vivenciados para inserção e manutenção no mercado de trabalho, trazendo maior compreensão sobre suas percepções e preferências, e sobre a diversidade geracional que pode estar relacionada à discriminação em função da idade (Angus \& Reeve, 2006).

\section{Conclusões}

O objetivo geral deste artigo foi analisar como se encontram configuradas as dimensões do comprometimento organizacional em relação às percepções temporais de jovens trabalhadores assistidos pelo ESPRO na cidade de Recife (PE). Diante de metodologia quantitativa, estudo de caso e análise estatística descritiva e bivariada, os resultados da pesquisa sugerem que há correlações significativas entre os construtos de comprometimento organizacional e de percepções temporais, no entanto, essas são discretas e envolvem principalmente o comprometimento afetivo. Esse dado é importante no sentido de que, considerando a predominância do comprometimento afetivo no público estudado, as percepções temporais são influenciadas por esse tipo de vinculação à organização, podendo resultar em situações de maior ou menor adequação ao ambiente de trabalho. 
Considerando as variáveis sociodemográficas, apesar de existirem correlações significativas no que tange ao comprometimento organizacional, essas são de baixa intensidade, corroborando com Meyer e Allen (1991) e Meyer et al. (2002), que afirmam serem essas relações baixas ou pouco consistentes. Por outro lado, as percepções temporais apresentaram maiores correlações com características pessoais, destacando-se correlações positivas com as variáveis sexo, escolaridade e ramo de atuação.

Em relação ao comprometimento organizacional, os jovens trabalhadores demonstraram ser predominantemente do tipo afetivo (média=3,62), o que corrobora com estudos como de Bastos (1993) e Rocha e Paiva (2016), significando que esses jovens se identificam com as empresas nas quais trabalham, com forte sentimento de pertença e desejo de contribuir de forma ativa para os objetivos. Esse resultado pode estar ligado ao próprio momento do jovem no qual a formação de amizades, o contato com outras pessoas e a referência às figuras de autoridade e liderança são importantes para sua formação como pessoas e trabalhadores. Esse dado é confirmado ao verificar que a maior perda, caso venham a se desligar da organização, está associada à perda dos contatos estabelecidos no ambiente.

Por sua vez, as percepções temporais dos jovens trabalhadores estudados revelam preferências por comportamentos monocrônicos, rápidos e pontuais, com ênfase no passado, sendo predominantes as vivências de arrastamento relacionadas à liderança, o que pode estar ligado à situação de vulnerabilidade social e ao momento de transição e questionamentos vivenciados nessa fase da vida.

\subsection{Limitações da Pesquisa}

Pode ser considerada uma limitação deste estudo o fato de serem abordados apenas os jovens assistidos pelo ESPRO, que possuem um perfil característico, uma vez que existem diversas "juventudes" que podem ser exploradas; além do fato de utilizar dados apenas da filial de Recife. Além disso, aliar outros métodos de coleta, como entrevistas, enriqueceria os achados e permitiria pensar outras relações entre os construtos abordados.

\subsection{Sugestões para Pesquisas Futuras}

Como sugestões de estudos futuros seria interessante complementar a análise com dados qualitativos, através de entrevistas, por exemplo, que possam enriquecer os dados aqui expostos e possibilitar comparações. Dentro de uma vertente quantitativa, seria possível o emprego de técnicas multivariadas, possivelmente associando outros fatores mediadores, que poderiam esclarecer os caminhos e a força das correlações encontradas.

Sugere-se, ainda, contemplar jovens que vivem em outros contextos e realidades, diferentes daquela comum aos jovens do ESPRO, além de analisar dados de outras filiais da instituição, permitindo comparações entre regiões do Brasil, o que pode enriquecer pesquisas que abordam o comprometimento organizacional e as percepções temporais desses jovens.

Outra sugestão é o estudo, no público aqui contemplado, de temas que auxiliem a caracterizar o que leva um jovem a desempenhar melhor/pior suas funções e a entender suas vivências no trabalho, como é o caso de justiça organizacional e atitudes retaliatórias.

\section{Referências}

Amazarray, M.R., Dutra-Thomé, L., Souza, A.P.L.D., Poletto, M., \& Koller, S.H.(2009). Aprendiz versus Trabalhador: Adolescentes em processo de aprendizado. Psicologia: Teoria e Pesquisa, 25(3), 329-338. Angus, J., \& Reeve, P.(2006). Ageism: A threat to "aging well" in the 21st century. Journal of Applied Gerontology, 25(2), 137-152.

Apergis, N.(2016). Unemployment and Organizational Commitment: evidence from a panel of Australian manufacturing firms. Review of Economic Analysis, 8, 135-152.

Barbosa, J.K.D.(2017). Temos todo tempo do mundo? Um estudo sobre percepções temporais e prazer e sofrimento com jovens trabalhadores. Dissertação (Mestrado em Administração). Universidade Federal de Minas Gerais.

Barling, J., Kelloway, E.K., \& Frone, M.R.(2005). Editor's Overviews: special populations. In: Barling, J.; Kelloway, E.K.; \& Frone, M.R. (eds.), Handbook of work stress, 401-404. Thousand Oaks: Sage.

Bastos, A.V.B.(1993). Comprometimento Organizacional: um balanço dos resultados e desafios que cercam essa tradição de pesquisa. Revista de Administração de Empresas, 33(3), 52-64.

Bastos, A.V.B., Siqueira, M.M.M., Medeiros, C.A.F., \& Menezes, I.G.(2008). Comprometimento 
Organizacional. In: Siqueira, M.M.M.(org.). Medidas do comportamento organizacional: ferramentas de diagnóstico e gestão. Porto Alegre: Artmed, 49-95.

Bauman, Z. (2007). Tempos líquidos. Rio de Janeiro: Jorge Zahar.

Bluedorn, A.C., \& Jaussi, K.S.(2007). Organizationally Relevant Dimensions of time across levels of analysis, In Dansereau, F., \& Yammarino, F.J.(orgs.), Multi-Level Issues in Organizations and Time. Research in multi-level issues. Elsevier, Oxford, 6, 187-223.

Botelho, R.D., \& Paiva, K.C.M.(2011). Comprometimento organizacional: um estudo no Tribunal de Justiça do Estado de Minas Gerais. Revista de Administração Pública, 45(5), 1249-1283.

Coimbra, C.C., Bocco, F., \& Nascimento, M.L.(2005). Subvertendo o conceito de adolescência. Arquivos Brasileiros de Psicologia, 57(1), 2-11.

Dessler, G.(1996). Conquistando o Comprometimento: Como construir e manter uma força de trabalho competitiva. São Paulo: Makron Books.

Dias, D.S.D., \& Marques, A.L.(2002). Múltiplos Comprometimentos: Um Estudo com Profissionais e Gerentes de uma Grande Empresa do Setor Metal-Mecânico. In: Anais... XXVIEnANPAD, Salvador.

Elias, N.(1998). Sobre o tempo. Rio de Janeiro: Jorge Zahar Ed.

Leccardi, C.(2005). Por um novo significado do futuro: Mudança social, jovens e tempo. Tempo Social, 17(2), 35-57.

Leite, A.M.A.A., Ferreira Filho, J., Cabral, A.C. de A., dos Santos, S.M., \& Pessoa, M.N.M.(2015). Visão compartilhada e comprometimento organizacional: um estudo de caso na Embracon - empresa brasileira de consórcios. Revista de Administração da UFSM, 8(3), 482-498.

Lombardi, A.R., \& Hanashiro, D.M.M.(2010). Policronicidade no ambiente organizacional - uma visão conceitual. EnEO, 6, 2010, Florianópolis. Anais... Florianópolis: ANPAD.

Magalhães, A.F., de Andrade, C.R., \& Saraiva, L.A.S.(2017). Inclusão de minorias nas organizações de trabalho: análise semiótica de uma estratégia de recrutamento de uma multinacional de fast food. TPATeoria e Prática em Administração, 7(2), 12-35.

Medeiros, C.A.F., Albuquerque, L.G., Marques, G.M., \& Siqueira, M.(2002). Comprometimento organizacional: o estado da arte da pesquisa no Brasil. In: Anais... XXVI EnANPAD, Salvador.

Meyer, J.P., \& Allen, N.J.(1987). A longitudinal analysis of the early development and consequences of organizational commitment. Canadian Journal of Behavioral Science, 19(2), 199-215.

Meyer, J.P., \& Allen, N.J.(1991). A three-component conceptualization of organizational commitment. Human Resource Management Review, Greenwich, 1(1), 61-89.

Meyer, J.P., Stanley, D.J., Herscovitch, L., \& Topolnytsky, L.(2002). Affective, continuance, and normative commitment to the organization: a meta-analysis of antecedents, correlates and consequences. Journal of Vocational Behavior, 61(1), 20-52.

Moscon, D. B.; Bastos, A. V. B. \& De Souza, J. J. (2012). É possível integrar, em um mesmo conceito, os vínculos afetivo e instrumental? 0 olhar de gestores sobre o comprometimento com a organização. Revista Organizações \& Sociedade, v.19, 357-373.

Mowday, R.T., Steers, R., Porter, L.W.(1979). The measurement of organizational commitment. Journal of Vocational Behavior, 14(2), 387-401.

Organização Internacional do Trabalho - OIT.(2009). Trabalho decente e juventude no Brasil, Brasília. Oliveira, S.R.(2011). Ponto de Partida: a juventude e o ingresso no mercado de trabalho. In: Ferraz, D.L.S., Oltramari, A.P., Ponchirolli, O.(org.). Gestão de pessoas e relações de trabalho. São Paulo: Atlas, 89- 112.

Oliveira, M.Z.D., \& Gomes, W.B.(2014). Estilos reflexivos e atitudes de carreira proteana e sem fronteiras nas organizações contemporâneas brasileiras. Revista Psicologia Organizações e Trabalho, 14(1), 105118.

Paiva, K.C.M., Dutra, M.R.S., Santos, A. de O., \& Barros, V.R.F.(2013). Proposição de escala de percepção temporal. Tourism \& Management Studies, 2, 523-535.

Paiva, K.C. M., Souza, C. M, O.(2016) Time perception: A study of young Brazilian workers. TMStudies [online]. 2016, 12 (1), 203-210.

Paiva, K.C.M., Pinto, D. de L., Dutra, M.R.S., \& Roquete, R.F.(2011). Quanto Tempo o Tempo Tem? Um estudo sobre o(s) tempo(s) de gestores do varejo em Belo Horizonte (MG). Organizações \& Sociedade, 18(59), 661-679.

Porter, L.W., Steers, K.W., \& Boulian, P.V.(1974). Organizational commitment, job satisfaction, and turnover among psychiatric technicians. Journal of Applied Psychology, 5(59), 603-609.

Rocha, E.S., \& Honório, L.C.(2015). Comprometimento com o trabalho: 0 caso dos chefes de seções de 
infraestrutura da UFMG. Revista Ciências Administrativas, 21(1), 237-261.

Rocha, M.S., \& Paiva, K.C.M.(2016). Relações fronteiriças entre as dimensões do comprometimento organizacional: contribuições de um estudo com jovens trabalhadores. In: Anais... EnANPAD, Costa do Sauípe.

Senge, P.M.(1998). A Quinta Disciplina. 2. a ed. São Paulo: Best Seller.

Silva, L.P., Castro, M.A.R., Dos-Santos, M.G. \& Neto, P.J.L.(2018). Comprometimento no trabalho e sua relação com a cultura organizacional mediada pela satisfação. Revista Brasileira de Gestão de Negócios, 20(3), 401-420.

Silva, R.S., Capelloza, A., \& Costa, L.V. (2014). O impacto do suporte organizacional e do comprometimento afetivo sobre a rotatividade. Revista de Administração IMED, 4(3), 314-329.

Siqueira, M.M.M.(2001). Comprometimento Organizacional Afetivo, Calculativo e Normativo: Evidências Acerca da Validade Discriminante de Três Medidas Brasileiras. In: Anais... EnANPAD, Campinas.

Thompson, E.P.(1991). Time, work-discipline and industrial capitalism. In: Customs in common: Studies in Traditional Popular Culture, 352-403. London: Merlin Press.

UNFPA.(2010). Direitos da população jovem: um marco para o desenvolvimento. 2d. Brasília: UNFPA Fundo de População das Nações Unidas.

Vasile, C.(2015). Time perception, cognitive correlates, age and emotions. Procedia - Social and Behavioral Sciences, 187(5), 695-699.

Vergara, S.C.(2004). Projetos e Relatórios de Pesquisa em Administração. 5a edição. São Paulo: Atlas.

Veriguine, N.R.; Basso, C.; Soares, D.H.P.(2014). Juventude e Perspectivas de Futuro: A Orientação Profissional no Programa Primeiro Emprego. Psicologia: Ciência e Profissão, 34(4), 1032-1044.

Walton, R. E. (1997). Do controle ao comprometimento no local de trabalho. In: Vroom, V.H, Gestão de pessoas, não de pessoal, 95-112. 
APÊNDICE A - Estatísticas descritivas das dimensões de comprometimento e resultados dos testes de comparação por tempo total de trabalho e Tempo de Empresa

\begin{tabular}{|c|c|c|c|c|c|c|c|}
\hline \multirow{2}{*}{$\begin{array}{c}\text { Comprometimento } \\
\text { Organizacional }\end{array}$} & \multirow[b]{2}{*}{ Categorias } & \multicolumn{3}{|c|}{ Tempo Total de Trabalho } & \multicolumn{3}{|c|}{ Tempo na Empresa } \\
\hline & & Média & $\begin{array}{l}\text { Desvio } \\
\text { Padrão } \\
\end{array}$ & $\begin{array}{c}\text { Teste de } \\
\text { comparação }\end{array}$ & Média & $\begin{array}{l}\text { Desvio } \\
\text { Padrão } \\
\end{array}$ & $\begin{array}{c}\text { Teste de } \\
\text { comparação }\end{array}$ \\
\hline \multirow{6}{*}{ Comprom. Afetivo } & Menos de 6 meses & 3,81 & 0,691 & \multirow{6}{*}{0,068} & 3,76 & 0,696 & \multirow{6}{*}{0,015} \\
\hline & de 6 meses a 1 ano & 3,58 & 0,684 & & 3,51 & 0,782 & \\
\hline & De 1,1 a 2 anos & 3,39 & 0,746 & & 3,35 & 0,811 & \\
\hline & de 2,1 a 3 anos & 3,37 & 0,937 & & - & - & \\
\hline & de 3,1 a 5 anos & 3,69 & 1,061 & & - & - & \\
\hline & Mais de 5,1 anos & 3,70 & 1,127 & & - & - & \\
\hline \multirow{6}{*}{ Comprom. Calculativo } & Menos de 6 meses & 3,12 & 0,758 & \multirow{6}{*}{0,004} & 3,01 & 0,844 & \multirow{6}{*}{0,007} \\
\hline & de 6 meses a 1 ano & 2,61 & 0,895 & & 2,68 & 0,869 & \\
\hline & De 1,1 a 2 anos & 2,75 & 0,786 & & 2,63 & 0,896 & \\
\hline & de 2,1 a 3 anos & 2,59 & 0,921 & & - & - & \\
\hline & de 3,1 a 5 anos & 2,76 & 1,277 & & - & - & \\
\hline & Mais de 5,1 anos & 3,07 & 1,007 & & - & - & \\
\hline \multirow{6}{*}{ PST } & Menos de 6 meses & 3,19 & 0,950 & \multirow{6}{*}{0,189} & 3,06 & 0,990 & \multirow{6}{*}{0,071} \\
\hline & de 6 meses a 1 ano & 2,85 & 1,019 & & 2,95 & 1,029 & \\
\hline & De 1,1 a 2 anos & 2,70 & 0,866 & & 2,41 & 0,939 & \\
\hline & de 2,1 a 3 anos & 2,80 & 1,167 & & - & - & \\
\hline & de 3,1 a 5 anos & 2,94 & 1,458 & & - & - & \\
\hline & Mais de 5,1 anos & 3,00 & 1,000 & & - & - & \\
\hline \multirow{6}{*}{ PIFO } & Menos de 6 meses & 3,15 & 0,966 & \multirow{6}{*}{0,000} & 3,05 & 1,007 & \multirow{6}{*}{0,001} \\
\hline & de 6 meses a 1 ano & 2,42 & 0,978 & & 2,54 & 1,005 & \\
\hline & De 1,1 a 2 anos & 2,86 & 1,014 & & 2,91 & 1,304 & \\
\hline & de 2,1 a 3 anos & 2,73 & 1,080 & & - & - & \\
\hline & de 3,1 a 5 anos & 3,10 & 1,624 & & - & - & \\
\hline & Mais de 5,1 anos & 3,10 & 0,854 & & - & - & \\
\hline \multirow{6}{*}{ PRO } & Menos de 6 meses & 3,03 & 0,872 & \multirow{6}{*}{0,081} & 2,96 & 0,926 & \multirow{6}{*}{0,034} \\
\hline & de 6 meses a 1 ano & 2,58 & 1,089 & & 2,62 & 1,033 & \\
\hline & De 1,1 a 2 anos & 2,75 & 0,990 & & 2,52 & 1,057 & \\
\hline & de 2,1 a 3 anos & 2,51 & 0,900 & & - & - & \\
\hline & de 3,1 a 5 anos & 2,51 & 1,133 & & - & - & \\
\hline & Mais de 5,1 anos & 3,13 & 1,250 & & - & - & \\
\hline \multirow{6}{*}{ PP } & Menos de 6 meses & 3,11 & 0,854 & \multirow{6}{*}{0,005} & 2,99 & 0,970 & \multirow{6}{*}{0,018} \\
\hline & de 6 meses a 1 ano & 2,62 & 1,092 & & 2,61 & 1,055 & \\
\hline & De 1,1 a 2 anos & 2,63 & 0,894 & & 2,61 & 0,850 & \\
\hline & de 2,1 a 3 anos & 2,35 & 1,146 & & - & - & \\
\hline & de 3,1 a 5 anos & 2,43 & 1,122 & & - & - & \\
\hline & Mais de 5,1 anos & 3,00 & 1,000 & & - & - & \\
\hline \multirow{6}{*}{ Comprom. Normativo } & Menos de 6 meses & 3,03 & 0,914 & & 2,97 & 0,884 & \\
\hline & de 6 meses a 1 ano & 2,67 & 0,947 & & 2,70 & 1,002 & \\
\hline & De 1,1 a 2 anos & 2,68 & 0,848 & 0078 & 2,47 & 0,989 & 0014 \\
\hline & de 2,1 a 3 anos & 2,64 & 0,978 & $0,0 / 0$ & - & - & 0,014 \\
\hline & de 3,1 a 5 anos & 3,01 & 1,338 & & - & - & \\
\hline & Mais de 5,1 anos & 3,43 & 1,380 & & - & - & \\
\hline
\end{tabular}

Fonte: Dados da pesquisa 
APÊNDICE B - Estatísticas descritivas das dimensões de percepções temporais e resultados dos testes de comparação por ramo da empresa

\begin{tabular}{|c|c|c|c|c|}
\hline Percepção Temporal & Ramo & Média & $\begin{array}{l}\text { Desvio } \\
\text { Padrão }\end{array}$ & $\begin{array}{c}\text { Teste de } \\
\text { Comparação }\end{array}$ \\
\hline \multirow{5}{*}{ Policronia } & Serviço ou administração pública & 3,04 & 0,602 & \multirow{5}{*}{0,831} \\
\hline & Indústria & 3,09 & 0,607 & \\
\hline & Comércio & 3,15 & 0,476 & \\
\hline & Bancos, instituição financeiras ou agências de crédito & 3,21 & 0,427 & \\
\hline & Outros & 3,41 & 0,551 & \\
\hline \multirow{5}{*}{ Velocidade } & Serviço ou administração pública & 3,36 & 0,585 & \multirow{5}{*}{0,044} \\
\hline & Indústria & 3,67 & 0,623 & \\
\hline & Comércio & 3,56 & 0,737 & \\
\hline & Bancos, instituição financeiras ou agências de crédito & 3,73 & 0,553 & \\
\hline & Outros & 3,62 & 0,679 & \\
\hline \multirow{5}{*}{ Pontualidade } & Serviço ou administração pública & 3,91 & 0,813 & \multirow{5}{*}{0,013} \\
\hline & Indústria & 4,49 & 0,768 & \\
\hline & Comércio & 4,13 & 0,726 & \\
\hline & Bancos, instituição financeiras ou agências de crédito & 4,53 & 0,651 & \\
\hline & Outros & 4,34 & 1,190 & \\
\hline \multirow{5}{*}{ Profundidade } & Serviço ou administração pública & 3,17 & 0,240 & \multirow{5}{*}{0,588} \\
\hline & Indústria & 3,06 & 0,534 & \\
\hline & Comércio & 3,07 & 0,464 & \\
\hline & Bancos, instituição financeiras ou agências de crédito & 3,11 & 0,459 & \\
\hline & Outros & 3,05 & 0,605 & \\
\hline \multirow{5}{*}{ Arrastamento } & Serviço ou administração pública & 4,01 & 0,704 & \multirow{5}{*}{0,091} \\
\hline & Indústria & 4,32 & 0,729 & \\
\hline & Comércio & 4,08 & 0,709 & \\
\hline & Bancos, instituição financeiras ou agências de crédito & 4,44 & 0,666 & \\
\hline & Outros & 4,28 & 1,048 & \\
\hline \multirow{5}{*}{ Sincronia } & Serviço ou administração pública & 3,98 & 0,777 & \multirow{5}{*}{0,190} \\
\hline & Indústria & 4,48 & 0,929 & \\
\hline & Comércio & 4,13 & 0,917 & \\
\hline & Bancos, instituição financeiras ou agências de crédito & 4,50 & 0,733 & \\
\hline & Outros & 4,36 & 1,118 & \\
\hline \multirow{5}{*}{ Liderança } & Serviço ou administração pública & 4,26 & 0,758 & \multirow{5}{*}{0,096} \\
\hline & Indústria & 4,53 & 0,882 & \\
\hline & Comércio & 4,24 & 0,753 & \\
\hline & Bancos, instituição financeiras ou agências de crédito & 4,60 & 0,927 & \\
\hline & Outros & 4,60 & 1,266 & \\
\hline \multirow{5}{*}{ Condução } & Serviço ou administração pública & 3,87 & 0,805 & \multirow{5}{*}{0,250} \\
\hline & Indústria & 4,00 & 0,775 & \\
\hline & Comércio & 3,91 & 0,780 & \\
\hline & Bancos, instituição financeiras ou agências de crédito & 4,29 & 0,738 & \\
\hline & Outros & 3,90 & 0,962 & \\
\hline
\end{tabular}

Fonte: Dados da pesquisa. 
APÊNDICE C - Correlações entre os dados demográficos e as dimensões de Comprometimento Organizacional e Percepções de Tempo

\begin{tabular}{|c|c|c|c|c|c|c|c|c|c|}
\hline CORRELAÇÕES & & SEXO & IDADE & $\begin{array}{c}\text { ESTADO } \\
\text { CIVIL }\end{array}$ & ESCOL. & COR & $\begin{array}{c}\text { T. TOT. } \\
\text { DE } \\
\text { TRAB. }\end{array}$ & T. EMP. & $\begin{array}{c}\text { T. } \\
\text { CARGO } \\
\end{array}$ \\
\hline \multirow{2}{*}{ COMP. AFET. } & Coef. de Cor. & 0,053 & $-0,055$ & $-0,025$ & 0,03 & $-0,059$ &,$- 195^{* *}$ &,$- 194^{* *}$ &,$- \mathbf{1 7 8}^{* *}$ \\
\hline & Sig. (2 extremidades) & 0,426 & 0,413 & 0,712 & 0,65 & 0,375 & 0,004 & 0,004 & 0,008 \\
\hline \multirow{2}{*}{ PST } & Coef. de Cor. & $-0,082$ & $-0,037$ & $-0,045$ & $-0,079$ & 0,036 &,$- 165^{*}$ & $-0,111$ & $-0,106$ \\
\hline & Sig. (2 extremidades) & 0,219 & 0,583 & 0,503 & 0,236 & 0,585 & 0,014 & 0,097 & 0,115 \\
\hline \multirow{2}{*}{ PIFO } & Coef. de Cor. &,$- 189^{* *}$ & $-0,064$ & $-0,046$ & $-0,076$ & 0,052 &,$- 160^{*}$ &,$- \mathbf{2 0 8}^{* *}$ &,$- \mathbf{1 7 6}^{* *}$ \\
\hline & Sig. (2 extremidades) & 0,004 & 0,342 & 0,489 & 0,254 & 0,436 & 0,017 & 0,002 & 0,009 \\
\hline \multirow{2}{*}{ PRO } & Coef. de Cor. & $-0,098$ &,$- \mathbf{1 5 1}^{*}$ &,$- 1^{\prime} 3^{*}$ & $-0,107$ & 0,016 &,$- 157^{*}$ &,$- \mathbf{1 7 4}^{* *}$ &,$- 150^{*}$ \\
\hline & Sig. (2 extremidades) & 0,139 & 0,024 & 0,031 & 0,106 & 0,815 & 0,019 & 0,009 & 0,026 \\
\hline \multirow{2}{*}{ PP } & Coef. de Cor. & $-0,112$ & $-0,112$ & $-0,023$ &,$- 201^{* *}$ & 0,084 &,$- 250^{* *}$ &,$- 183^{* *}$ &,$- \mathbf{1 7 8}^{* *}$ \\
\hline & Sig. (2 extremidades) & 0,09 & 0,095 & 0,735 & 0,002 & 0,207 & $\mathbf{0}$ & 0,006 & 0,008 \\
\hline \multirow{2}{*}{ COMP. CALC. } & Coef. de Cor. & $-0,127$ & $-0,109$ & $-0,071$ &,$- 133^{*}$ & 0,043 &,$- 217^{* *}$ &,$- 208^{* *}$ &,$- \mathbf{1 8 9}^{* *}$ \\
\hline & Sig. (2 extremidades) & 0,056 & 0,103 & 0,287 & 0,046 & 0,519 & 0,001 & 0,002 & 0,005 \\
\hline \multirow{2}{*}{ COMP. NORM. } & Coef. de Cor. &,$- 170^{*}$ & $-0,056$ & $-0,015$ &,$- 216^{* *}$ & 0,038 &,$- 147^{*}$ &,$- 196^{* *}$ &,$- \mathbf{1 5 4}^{*}$ \\
\hline & Sig. (2 extremidades) & 0,01 & 0,4 & 0,817 & 0,001 & 0,571 & 0,029 & 0,003 & 0,022 \\
\hline \multirow{2}{*}{ POLICRONIA } & Coef. de Cor. &, $180^{* *}$ & $-0,064$ & $-0,094$ & 0,108 & 0,031 &, $182^{* *}$ & 0,104 & 0,075 \\
\hline & Sig. (2 extremidades) & 0,006 & 0,342 & 0,156 & 0,104 & 0,641 & 0,007 & 0,118 & 0,267 \\
\hline \multirow{2}{*}{ VELOCIDADE } & Coef. de Cor. & 0,095 & $-0,028$ & 0,047 &, $211^{* *}$ & 0,006 & 0,013 & $-0,03$ & $-0,064$ \\
\hline & Sig. (2 extremidades) & 0,154 & 0,671 & 0,483 & 0,001 & 0,929 & 0,849 & 0,653 & 0,347 \\
\hline \multirow{2}{*}{ PONTUALIDADE } & Coef. de Cor. &, $167^{*}$ & $-0,047$ & 0,072 & 0,127 & $-0,077$ & $-0,045$ & $-0,128$ &,$- 166^{*}$ \\
\hline & Sig. (2 extremidades) & 0,012 & 0,483 & 0,28 & 0,056 & 0,248 & 0,502 & 0,055 & 0,013 \\
\hline \multirow{2}{*}{ PROFUNDIDADE } & Coef. de Cor. & ,131* & $-0,041$ & $-0,057$ & ,136* & ,151* & 0,012 & 0,01 & $-0,037$ \\
\hline & Sig. (2 extremidades) & 0,048 & 0,537 & 0,394 & 0,041 & 0,023 & 0,856 & 0,879 & 0,588 \\
\hline \multirow{2}{*}{ ARRASTAMENTO } & Coef. de Cor. &, $141^{*}$ & 0,048 & $-0,018$ &, $217^{* *}$ & $-0,002$ & $-0,011$ & $-0,114$ & $-0,128$ \\
\hline & Sig. (2 extremidades) & 0,034 & 0,472 & 0,786 & 0,001 & 0,98 & 0,875 & 0,089 & 0,057 \\
\hline \multirow{2}{*}{ SINCRONIA } & Coef. de Cor. & 0,123 & 0,07 & 0,054 & $182^{* *}$ & 0,031 & 0,031 & $-0,069$ & $-0,092$ \\
\hline & Sig. (2 extremidades) & 0,064 & 0,294 & 0,416 & 0,006 & 0,647 & 0,647 & 0,304 & 0,173 \\
\hline \multirow{2}{*}{ LIDERANÇA } & Coef. de Cor. & $167^{*}$ & $-0,004$ & $-0,014$ &, $157^{*}$ & $-0,032$ & $-0,027$ & $-0,116$ & $-0,102$ \\
\hline & Sig. (2 extremidades) & 0,012 & 0,956 & 0,832 & 0,017 & 0,634 & 0,684 & 0,082 & 0,132 \\
\hline \multirow{2}{*}{ CONDUÇÃO } & Coef. de Cor. & 0,075 & 0,069 & $-0,056$ & ,228** & 0,003 & $-0,019$ & $-0,084$ & $-0,128$ \\
\hline & Sig. (2 extremidades) & 0,259 & 0,306 & 0,404 & 0,001 & 0,964 & 0,779 & 0,207 & 0,057 \\
\hline
\end{tabular}

**. A correlação é significativa no nível 0,01.

*.A correlação é significativa no nível 0,05.

Fonte: Dados da pesquisa. 